\title{
TRACING THE HISTORICAL ORIGIN OF JOSEON MUMMIES CONSIDERING THE STRUCTURAL SIMILARITIES BETWEEN THE BURIAL SYSTEMS OF KOREAN AND CHINESE DYNASTIES
}

\author{
Chang Seok $\mathrm{OH}^{1}$, In Uk Kang ${ }^{2}$, Jong Ha Hong ${ }^{1}$, Sergey Slepchenko ${ }^{3,4,5}$, \\ Jun Bum Park ${ }^{6}$, Dong Hoon SHIN ${ }^{1}$ \\ ${ }^{1}$ Laboratory of Bioanthropology, Paleopathology and History of Diseases, \\ Department of Anatomy / Institute of Forensic Science, \\ Seoul National University College of Medicine, Seoul, South Korea \\ ${ }^{2}$ Department of History, Kyung Hee University, Seoul, South Korea \\ ${ }^{3}$ Institute of the Problems of Northern development; \\ ${ }^{4}$ Tuymen Scientific Center, Siberian Branch of the Russian Academy of Sciences, \\ Tyumen, Russia \\ ${ }^{5}$ Paleopoisk Ltd, Novosibirsk, Russia \\ ${ }^{6}$ Sangmyung University Seoul Industry Academic Cooperation Foundation, \\ Seoul, South Korea
}

\begin{abstract}
Joseon mummies have proved to be excellent subjects for scientific research on the health and disease statuses of pre-modern Korean peoples. Despite its academic significance, the origins of the Hoegwakmyo tomb in which the Joseon mummy was discovered have not yet been entirely revealed. Meanwhile, over the past several decades, there have been some reports on mummies and cultural artifacts preserved very well in the tombs of several Chinese dynasties (especially Song, Yuan, Ming and Qing). Although the Chinese tombs were very diverse in structure, we note that some graves among them were structurally very similar to Joseon Hoegwakmyo tombs. Before the Hoegwakmyo tomb in Korea, there were already similar tombs in China, inside which dead persons were mummified like the Joseon mummies. Considering that the Hoegwakmyo tomb of the Joseon Dynasty was established by the influence of the Confucian ideology, the Korean and Chinese mummies might share common cultural origins in history.
\end{abstract}

Keywords: Korea; China; mummy; Joseon; Song; Yuan; Ming; Qing; lime-soil mixture; Hoegwakmyo; sticky-rice-paste sealed tomb 


\section{INTRODUCTION}

Over the course of the past several decades, well-preserved mummies have been discovered in tombs dating to the Joseon Dynasty (1392-1910 CE) (Fig. 1). The most unique feature of Korean mummies is their perfect preservation status [16]. Information gleaned on various physical and pathological traits is invaluable data for anthropologists who have been endeavouring to reveal the interactions between man and his environment in history.

For the past several years, various aspects of the Korean mummies have been examined by investigators of different research fields (Fig. 2). By anatomical, histological, radiological and molecular investigations, signs of congenital or acquired diseases have been identified $[2,3,5,6,9,10,11,13]$. The above-noted research techniques employed in collaborative research have driven the expansion of our understanding of Joseon societies to an unexpectedly high level. Without mummy research, fascinating and historically constructive information would have never been obtained in South Korea.

Despite its academic significance, the historical origin of the Joseon mummy has not yet been entirely revealed. The only thing that has been confirmed to date is that the Hoegwakmyo tomb in which Korean mummies were discovered was established by the influence of the Confucian ideology during the Joseon period [14]. Actually, based on this fact alone, it is not surprising that tombs and mummies similar to Hoegwakmyo and Korean mummies also have been discovered in China. Nonetheless, there is still not enough data known to scholars outside China.

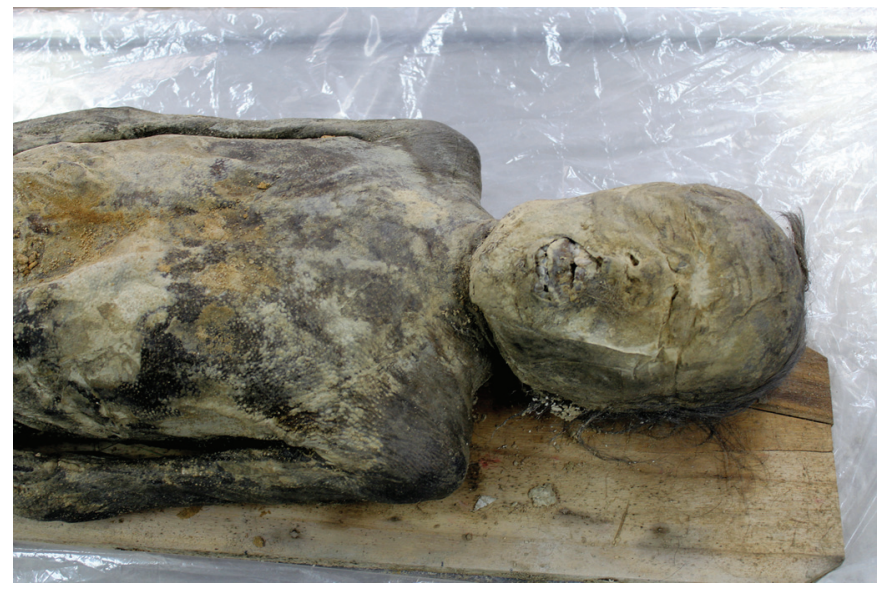

Figure 1. Perfect preservation status of a Korean mummy discovered at Andong. 


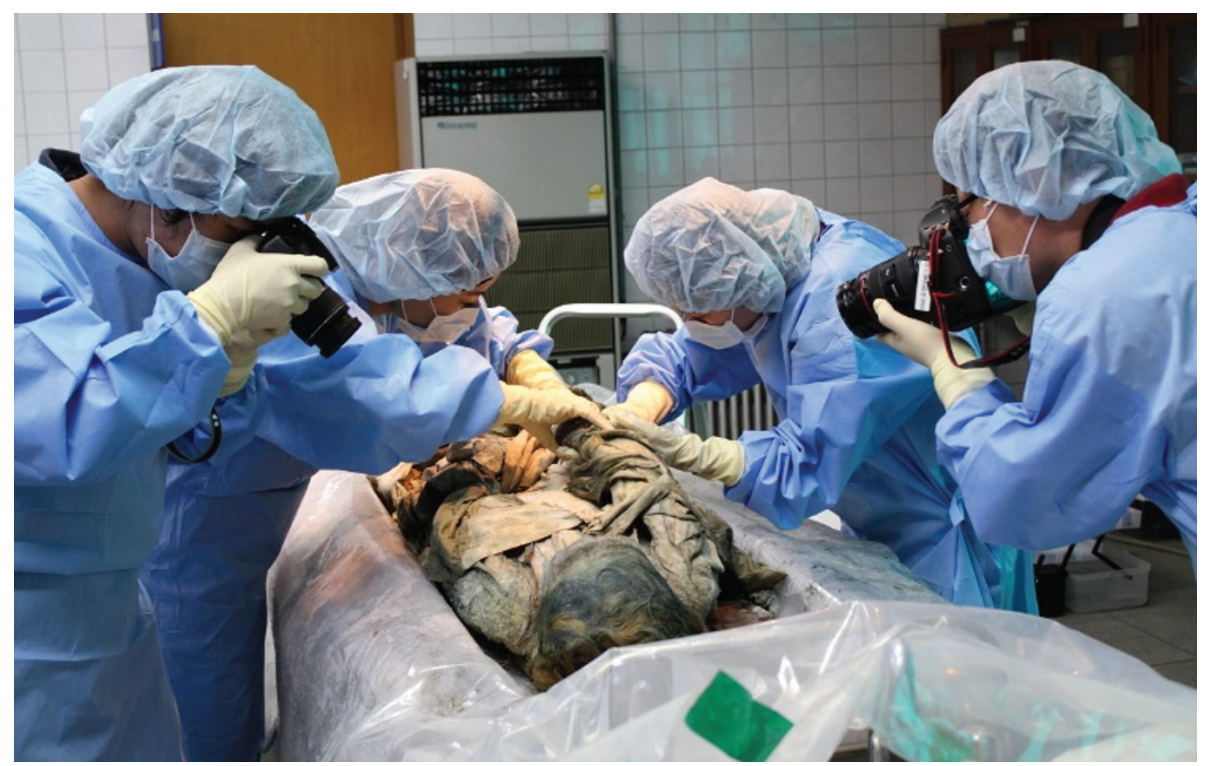

Figure 2. Mummy investigation by dress-historians before anthropological studies began. The mummy was discovered at Mungyeong, South Korea.

In this regard, our current review of Chinese tombs and mummies of the Song, Yuan, Ming and Qing dynasties is meaningful to the concerned scholars. Actually, we can propose herewith that earlier than the introduction of the Hoegwakmyo tomb in Korea, very similar tombs were constructed on the Chinese mainland as well, and inside them, dead persons were also mummified like those discovered in the Hoegwakmyo tomb of the Joseon dynasty.

\section{THE JOSEON TOMB}

The mechanism of mummification inside the Joseon tombs has yet to be fully revealed. From the historical perspective, we found that there were no traditions of dead body embalming in Korea, which made us rule out the possibility that the Joseon people were artificially mummified after death [3]. As Korea is not a dry land or in the permafrost zone, the Joseon mummy could not be classified as any category of natural mummification [13].

In fact, we must note that Joseon mummies have been found exclusively in graves with a unique structure (Hoegwakmyo). Korean archaeologists found that whenever a Joseon mummy was discovered at the excavation site, the coffin was completely encapsulated by a lime-soil-mixture barrier [13]. There- 
fore, we suspected that the Joseon mummies were not formed by any known mechanism of mummification but in a unique sociocultural environment rather (Fig. 3).

Historically, the establishment of the Hoegwakmyo tomb was closely related to the political rise of NeoConfucianists in Korean history. In the $14^{\text {th }}$ century, armed with high-level philosophical thinking and intellectual beliefs, they attacked the Buddhists, who had been dominant in Korean politics to date. In 1392, the Neo-Confucianists finally succeeded in founding a new kingdom, the Joseon Dynasty. Under the new leadership, the Buddhist rituals of the Goryeo period (918-1392

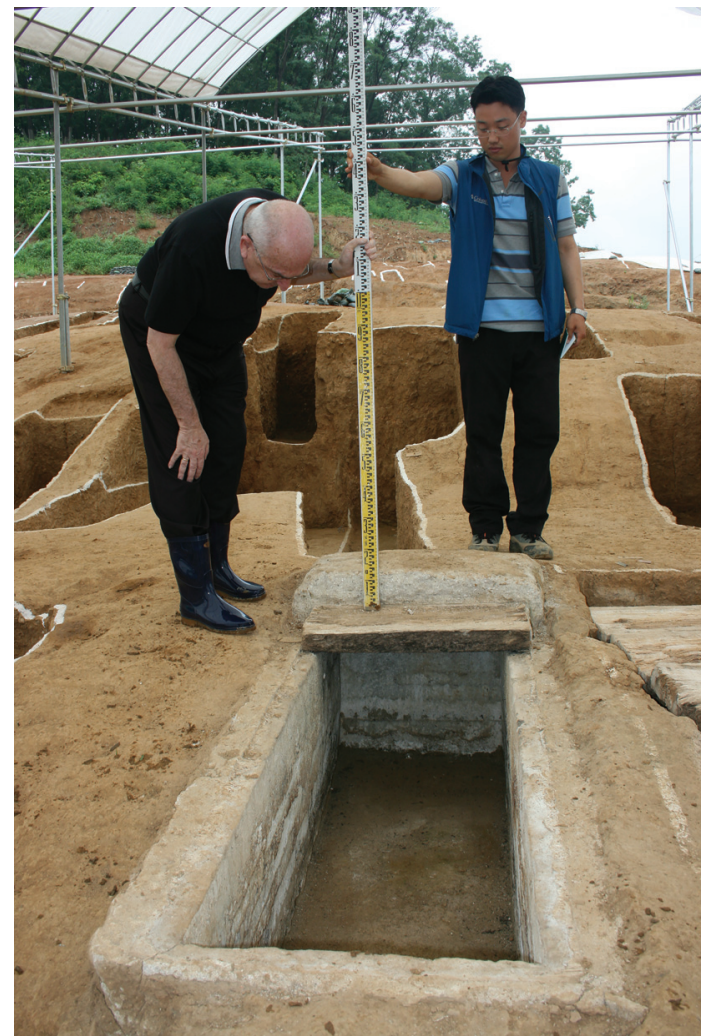

Figure 3. A Joseon tomb sealed by a lime-soil mixture barrier in the excavation site. The coffin has already been removed from the site.

$\mathrm{CE})$ were immediately and thoroughly purged [14].

Indeed, the Confucianists were religiously so devout that they adhered even to the trivial points of Confucian rituals. It was in this context that the Hoegwakmyo tomb was introduced into the Korean society. In fact, Zhu Xi (1130$1200 \mathrm{CE}$ ) of China, one of the co-founders of the Neo-Confucian ideology, insisted that Hoegwakmyo was the best burial system for Confucianism followers. As Joseon Neo-Confucianists respected Zhu Xi as a great proponent of their social belief system, the Hoegwakmyo tomb was rapidly accepted among them. With remarkable repercussions, it became a central constituent of Confucian funeral rituals in the Joseon society.

However, even many years after its introduction, the Hoegwakmyo tomb still had not become part of the mainstream of Confucianist ritual in the Joseon 
society. In the earliest period of its introduction, the coffin, contrary to Zhu Xi's recommended sequence, was first placed in the burial pit and then sealed by the lime-soil mixture [4] (Fig. 4A). As time and trial and error proceeded, however, the lime-soil-mixture wall in the burial pit came to be formed first, after which the coffin was inserted [4] (Fig. 4B). Gradually, Neo-Confucianists would establish Hoegwakmyo as the principal burial system of the Joseon Dynasty.

The Joseon people constructed the Hoegwakmyo tombs generally according to the Confucian rituals recorded in the Jujagare (Zhouzijiali in Chinese), the
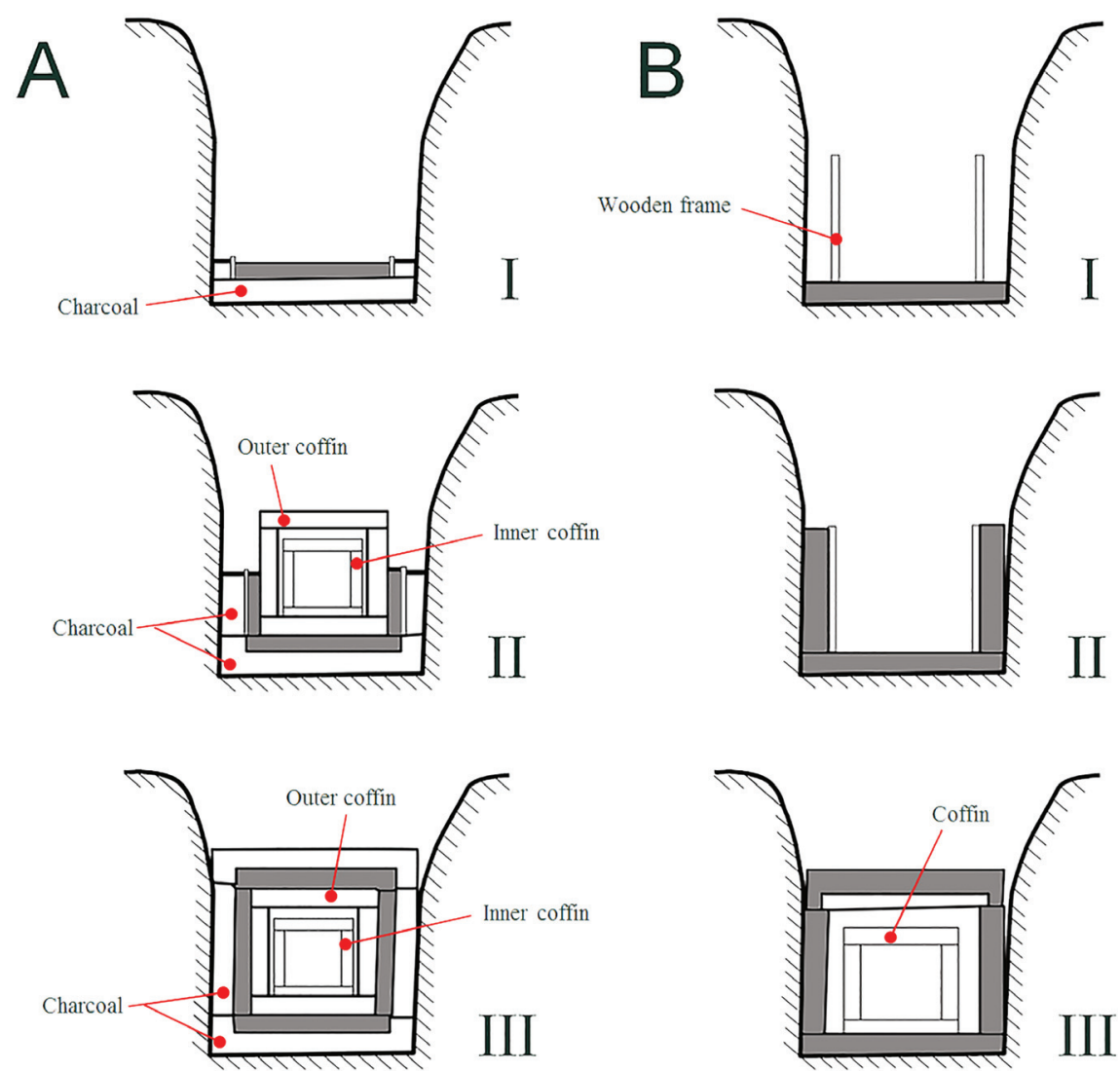

Figure 4. Difference in Hoegwakmyo grave construction (A) at the initial and (B) late stages. In (A) and (B), each step-by-step figure (I, II and III) shows how the grave was actually made by the Joseon people. The areas marked in grey are the parts made of lime-soil mixture. In (A), the coffins were placed in the burial pit first, and then the lime-soil mixture walled the coffins. (B) shows that the lime-soil wall was made first, and then the coffin was put inside the secured space. The figures are re-drawn based on those in Kim W.L., 2016 [4]. 


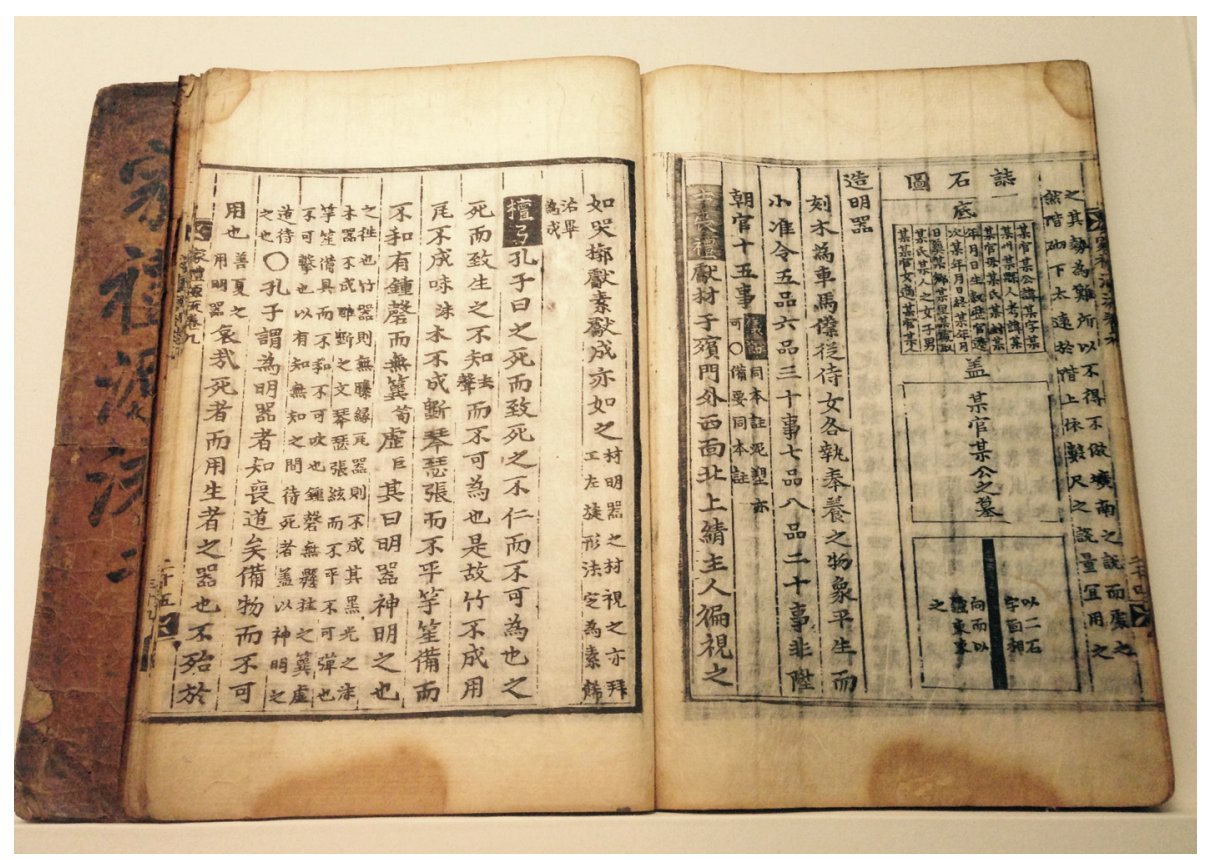

Figure 5. A ritual book (Garyewollyu) highly respected by Joseon Neo-Confucianists. This book is based on the contents of Jujagare (Zhuzi jiali in China) by Zhu Xi.

famous ritual guidebook written by Zhu Xi (Fig. 5). He recommended this tomb to his followers as a very low-cost means for protecting the integrity of the tomb from intruders [14]. However, contrary to the founder's wishes, and despite the good faith and religious passion that had gone into the tombs' construction, the bodies became mummified. Researchers have pointed to the unique structure of the Hoegwakmyo tomb with its lime-soil-mixture barrier as an explanation for mummification.

\section{CHINESE MUMMIES OF THE DYNASTIC PERIOD}

Mummies are not an historical phenomenon seen only in South Korea. Various types of mummies have also been reported from many other Asian countries. Among Asian mummies, there are those of Buddhist monks reported from Southeast Asia, China and Japan. The discovery of mummies in the permafrost area of Siberia has also contributed to our knowledge of the medieval aboriginal people in that area [15]. 
In China, various kinds of mummies formed under different circumstances have also been reported. A female mummy was discovered in a Mawangdui tomb dating to the Han Dynasty (206 BCE to $220 \mathrm{CE}$ ) [1]. Naturally formed mummies have also been found in the dry region of Loulan in the Tarim Basin in Xinjiang province. Multiple inducing factors such as arid climate or salty soil have been posited as probable causes of such mummification [1].

Although some Chinese mummies have become globally famous, there are still others that have not been well recognized internationally. For example, Aufderheide [1] described mummies discovered in Chinese graves dating to the second millennium, particularly those representing the Song (9601279 CE), Yuan (1271-1368 CE), Ming (1368-1644 CE) and Qing (16441912 CE) dynasties [1]. There have also been some news reports covering the mummies and cultural artefacts preserved very well in the tombs of the same Chinese dynasties. (http://news.nationalgeographic.com/news/2011/03/ pictures/110310-wet-mummy-china-ming-science-mummies-tomb-chinese$\mathrm{road} /$ ). With the exception of Aufderheide's introductory explanation [1] and brief media coverage, however, the scientific and cultural properties of Chinese mummies are not well known outside academia.

To understand the actual origin of Hoegwakmyo tombs in Korea, we must consult the information available from the archaeological reports on mummies dating to the Song-to-Qing dynasties. It is noteworthy that some of the relevant Chinese tombs exhibit structural similarity to the Joseon tombs. Like the Hoegwakmyo type of tomb, they have a lime-soil-mixture barrier formed around the coffin.

In Chinese archaeology, they are of a type referred to as the sticky rice paste (or soup) sealed tomb considering the fact that the lime and soil had been mixed with boiling sticky-rice water [21]. According to Chinese archaeological reports, one of the earliest sticky rice paste sealed tombs was the Sun Siniangzi $\mathrm{mu}$ (tomb) found in Jiangyin city of Jiangsu province [17]. The grave was built in 1055 CE for a Northern Song Dynasty (960-1127 CE) bureaucrat's wife.

This discovery is important for revealing the origin of Hoegwakmyo tombs of Korea. As mentioned above, the establishment of Hoegwakmyo tombs was remarkably influenced by the introduction of the Jujagare, the ritual guidebook written by Zhu Xi. As this book was written in the Southern Song period (1127-1279 CE), Korean scholars traced the origin of the Hoegwakmyo tombs to this period. However, considering the estimated date of the Sun Siniangzi mu tomb, we must re-adjust the possible origin of the Hoegwakmyo tombs. As similar tombs had already appeared in the Northern Song period (960-1127 
CE) in Chinese history, the origin of the Hoegwakmyo tomb might have to be retraced somewhat further back.

\section{STICKY-RICE-PASTE-SEALED TOMBS}

In general, the structures of the Hoegwakmyo tombs in Korea were stereotypical and not greatly affected by the date of construction or the region. This is because the Joseon Neo-Confucianists followed the instructions in the Jujagare as much as they could while constructing the graves. Nevertheless, we note that the sticky rice paste sealed tombs found in the South China provinces were very diverse in structure (Fig. 6), and among them, some graves were structurally very similar to the Joseon Hoegwakmyo tombs.

A good example is the $\mathrm{Xu}$ Fan couple tomb built during the Ming Dynasty in 1533 (Fig. 6C). Archaeologists in Taizhou city discovered this tomb, which combined the wife's and husband's coffins side by side, the outer coffin being further sealed by a lime-soil-mixture barrier [18]. The structure of this tomb is obviously very similar to the Korean Hoegwakmyo tombs (Fig. 6C).

Other Ming Dynasty tombs of similar structure include the couple tombs of Li Xian Fang (Shanghai) (Fig. 6A), Liu Xiang (Taizhou) (Fig. 6B), and Sensenzhuang village (Taizhou) (Fig. 6D). As in the case of the Xu Fan couple tomb, the coffins were completely sealed with lime-soil mixed with sticky rice soup $[12,21]$. Considerable amounts of clothes and other cultural artefacts were also discovered inside the coffins $[18,21]$.

In the Xu Fan couple's tomb, the bodies were found in a perfectly preserved condition. The skin colour was light yellow, and the soft tissue was still elastic. Adipocytes in the mummified tissue, well-defined tracheal cartilage, and even cell nuclei were found by microscopic observation by histological analysis [18].

Let us regard another case of a typical second-millennium Chinese mummy described by archaeologists in China. In 1988, archaeologists discovered a $13^{\text {th }}$-century Southern Song Dynasty grave in De'an county in Jiangxi province. The grave had been constructed in 1274, just a few years before the fall of the Southern Song Empire. The mummified female recovered from the grave had been the wife of the official Wu Chou [23].

From a scientific standpoint, the body's tissues and organs were perfectly preserved. The body was soft and still flexible at each joint. According to Zhou et al. [23], this mummy differs from those of any other countries. They argued that the body had been perfectly preserved due to the complete sealing of the 
A
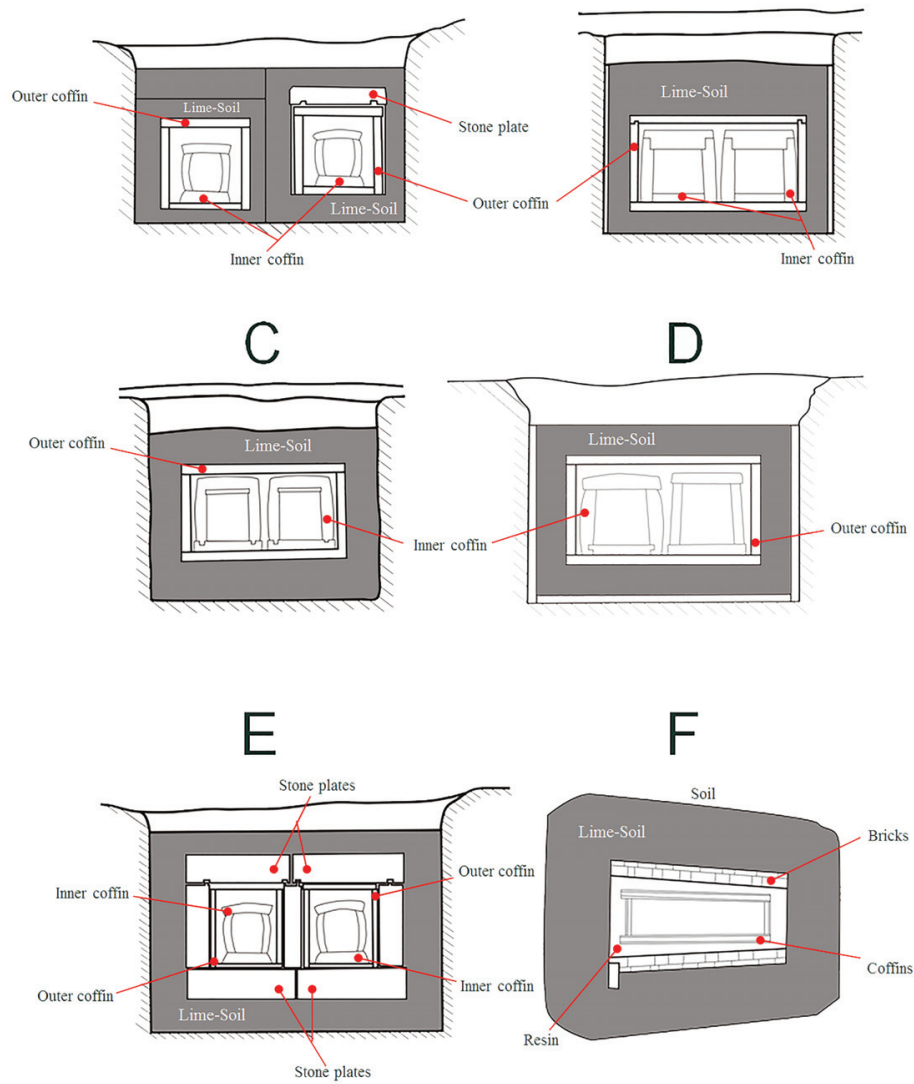

G

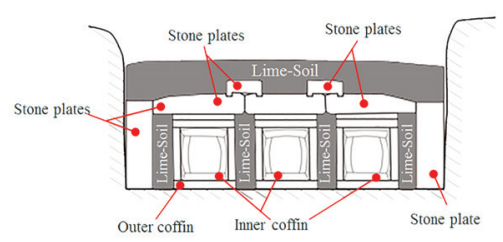

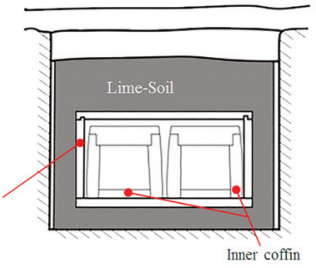

B

$\mathrm{D}$

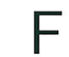

Soil

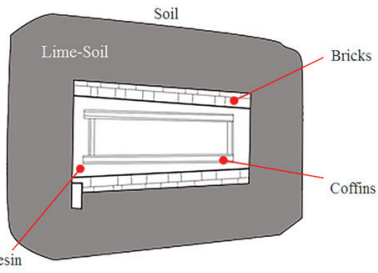

$\mathrm{H}$

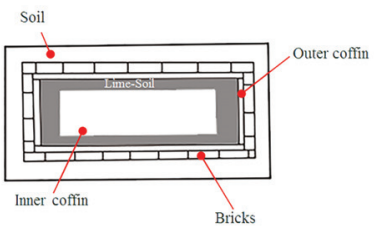

Figure 6. Diversity in tomb structures of the sticky rice soup tombs of China. Four tombs (from A to D) are similar to the Joseon Hoegwakmyo tombs, although not exactly the same. A - Li Xian Fang couple tomb (Shanghai), B - Liu Xiang couple tomb (Taizhou, Jiangsu), C - Xu Fan couple tomb (Taizhou, Jiangsu), D - Sensenzhuang tomb (Taizhou, Jiangsu), E - Li Xian Zhai couple tomb (Shanghai), F - Nanchang (Jiangxi), G - Zhu Shou Cheng couple (Shanghai), H - De'an (Jiangxi). The figures are re-drawn based on those in Shanghai Shi Wen Wu Guan Li Wei Yuan Hui, 2009 (A, E, G) [12]; Taizhou Municipal Museum, 1992 (B) [19]; Taizhou Municipal Museum, 1986 (C) [18];Taizhou Municipal Museum, 2013 (D) [21]; Taizhou Municipal Museum, 2003 (F) [20]; Zhou et al., 1999 (H) [23]. 
grave from the outside and that material such as lime or mercury inside the coffin might have also contributed.

Chinese scholars have reported impressive results on mummies. They successfully uncovered the medical signs of atherosclerosis in the Xu Fan mummy. Also, in paleoparasitological examinations performed on coprolite samples, they proved that the individual had suffered from multiple parasitic diseases [18]. Additional paleoparasitological studies have been conducted with other mummies of the Song and Ming dynasties, in the faeces of which ancient Clonorchis sp., Fasciolopsis sp., Ascaris sp., and Trichuris sp. parasite eggs were detected [7].

Considering both the quantity and quality of research results, the conservation status of Chinese mummies from sticky rice paste sealed tombs does not seem inferior to that of Joseon mummies. Most medical tests (CT, ancient DNA analysis, etc.) that have proven successful for Joseon mummy studies could be applied to studies on Chinese mummies in the future.

What was the mechanism of mummification inside sticky rice paste sealed tombs? As China, like South Korea, lacks proper natural conditions for natural mummification, the phenomenon seems exceptional. Various hypotheses have already been proposed. Some speculate that mummification might have been induced by multiple factors such as the complete sealing of the tomb from the outside, the constant temperature and humidity sustained inside the coffin, and others [18].

Others have pointed to the densely packed clothes inside the sticky rice paste sealed tombs as a key component of the mechanism of mummification [21, 22]. Actually, the coffins were filled with clothes so tightly that there was not much empty space left, thus inducing a severe oxygen-deficiency condition. This should have inhibited the proliferation of bacteria, thereby slowing down the process of decomposition and, thus, finally contributing to mummification $[21,22]$.

Moisture absorbents put inside the coffins and the bactericidal effect of lime, among other factors, also have been posited as causative factors in the preservation of human bodies and clothes inside sticky rice paste sealed tombs [21, 22]. Aufderheide [1] also claimed that the good preservation status of mummies might have been affected by an antiseptic technique popular in China at the time.

All of these proposed hypotheses are not unknown to us, South Korean scholars. As seen above, similar arguments about the causes of mummification 
have also been raised to solve the same mystery here. We note that the sticky rice paste sealed tombs in China, like the Hoegwakmyo tombs in South Korea, were also surrounded by a lime-soil-mixture barrier. If, as we guessed earlier, mummification occurring inside the Joseon tombs was really influenced by the Hoegwakmyo tomb's unique structure with the lime-soil-mixture barrier, we assume that mummification in the sticky rice paste sealed tombs might have been induced by the same process.

No matter how persuasive, what we have said here amounts only to a simple presumption about the mummification mechanism. To strengthen our hypothesis, investigators must establish in future studies whether the Chinese mummies were really formed by the same mechanism as the Korean mummies. The actual process of mummification inside sticky rice paste sealed tombs might also be revealed by archaeological experiments, possibly using a miniature grave and animal models as in our recent Korean mummy studies [8].

\section{CONCLUSIONS}

We have had the fortunate opportunity to study Korean mummies of the Joseon Dynasty. Through interdisciplinary research, we have obtained invaluable information concerning the health and disease statuses of Koreans who lived hundreds of years ago. In the wake of a series of scholarly achievements, most Koreans now agree on the academic value of Joseon mummy studies.

Despite its academic significance, the origins of the Hoegwakmyo tombs and the Joseon mummies have not been entirely revealed yet. The only thing that has been confirmed to date is that the Hoegwakmyo tomb in Korea was established under the influence of the prescriptions and descriptions in the Confucian ritual guidebook Jujagare written by $\mathrm{Zhu} \mathrm{Xi}$, a great Chinese scholar of the $12^{\text {th }}$ century.

In this regard, our current review of Chinese mummies of the Song, Yuan, Ming and Qing dynasties is meaningful to the scholars of both countries. In this study, we confirmed that the origins of the Hoegwakmyo tomb and Joseon mummies have to be retraced further back to the Northern Song period (960$1127 \mathrm{CE}$ ), and the presence of well-preserved mummies inside such tombs has also been reported by Chinese archaeologists.

Although information on the mummies found in the two countries has begun to be summarized and reported, more discussion is still needed to reach a consensus among scholars on the most basic facts on those mummies. For 
instance, although bodies found in sticky rice paste sealed tombs are generally regarded as mummies outside China [1], they are called simply ancient human corpses in China $[22,23]$.

\section{ACKNOWLEDGEMENTS}

This study was supported by the National Research Institute of Cultural Heritage, Korea (08D011Y-00110-2008), and the Basic Science Research Program through the National Research Foundation of Korea (NRF) funded by the Ministry of Education (2013R1A1A2009688). The first two authors (Oh CS and Kang IU) contributed equally to this study.

\section{REFERENCES}

1. Aufderheide A.C. (2003). The Scientific Study of Mummies. Cambridge: Cambridge University Press.

2. Kim M.J., Kim Y.-S., Oh C.S., Go J.-H., Lee I.S., Park W.-K., Cho S.-M., Kim S.-K., Shin D.H. (2015). Anatomical Confirmation of Computed TomographyBased Diagnosis of the Atherosclerosis Discovered in $17^{\text {th }}$ Century Korean Mummy. PLoS ONE, 10, 3, e0119474. https://doi.org/10.1371/journal.pone.0119474

3. Kim M.J., Park S.S., Bok G.D., Choi Y.H., Lee I.S., Shin K.J., Han G.R., Youn M., Han S.H., Kang I.W., Chang B.S., Cho Y.J., Chung Y.H., Shin D.H. (2006). Medieval mummy from Yangju. Archaeol Ethnol Anthropol Eurasia, 28, 1, 122-129. https://doi.org/10.1134/S156301100604013X

4. Kim W.L. (2016). Research on the Tomb Culture of the Gentry during the Joseon Dynasty. Seoul: Publishing Company Minsokwon.

5. Kim Y.-S, Lee I.S., Jung G.-U., Oh C.S., Yoo D.S., Lee W.J., Lee E.-J., Cha S.C., Shin D.H. (2014). Radiological Diagnosis of Congenital Diaphragmatic Hernia in $17^{\text {th }}$ century Korean Mummy. PLoS ONE, 9, 7, e99779. https://doi.org/10.1371/journal.pone.0099779

6. Lee E.-J., Oh C.S., Yim S.G., Park J.B., Kim Y.-S., Shin M.H., Lee S.D., Shin D.H. (2013). Collaboration of archaeologists, historians and bioarchaeologists during removal of clothing from Korean mummy of Joseon dynasty. Int J Hist Archaeol, 17, 1, 94-118. https://doi.org/10.1007/s10761-012-0211-0

7. Li Y. (1984). Zhong guo gu shi ji sheng chong xue yan jiu zhi zong shu. Acta Anthropologica Sinica, 3, 4, 407-411.

8. Oh C.S. and Shin D.H. (2014). Making Animal Model for Korean Mummy Studies. Anthropol Anz, 71, 4, 469-488. https://doi.org/10.1127/0003-5548/2014/0360 
9. Oh C.S., Lee S.J., Lee S.D., Kim M.J., Kim Y.-S., Lim D.-S., Shin D.H. (2013). Amplification of DNA remnants in mummified human brains from medieval Joseon tombs of Korea. Anthropol Anz, 70, 1, 57-81. https://doi.org/10.1127/0003-5548/2012/0225

10. Seo M., Araujo A., Reinhard K., Chai J.Y., Shin D.H. (2014). Paleoparasitological studies on Mummies of the Joseon Dynasty, Korea. Korean J Parasitol, 52, 3, 235-242. https://doi.org/10.3347/kjp.2014.52.3.235

11. Seo M., Oh C.S., Hong J.H., Chai J.-Y., Cha S.C., Bang Y., Cha I.G., Wi Y.G., Park J.M., Shin D.H. (2017). Estimation of Parasite Infection Prevalence of Joseon People by Paleoparasitological Data Updates from the Ancient Feces of Pre-modern Korean Mummies. Anthropol Sci, 125, 1, 9-14. https://doi.org/10.1537/ase.160920

12. Shanghai Shi Wen Wu Guan Li Wei Yuan Hui. (2009). Shanghai Ming Mu. Beijing: Wen wu chu ban she.

13. Shin D.H., Choi Y.H., Shin K.J., Han G.R., Youn M., Kim C.Y., Han S.H., Seo J.C., Park S.S., Cho Y.J., Chang B.S. (2003). Radiological analysis on a mummy from a medieval tomb in Korea. Ann Anat, 185, 4, 377-382. https://doi.org/10.1016/S0940-9602(03)80065-1

14. Shin M.H., Yi Y.S., Bok G.D., Lee E.-J., Spigelman M., Park J.B., Min S.-R., Shin D.H. (2008). How did mummification occur in bodies buried in tombs with a lime soil mixture barrier during the Joseon Dynasty in Korea? Mummies and Science World Mummies Research, Pena P.A., Martin R.M. and Rodriguez A.R. (eds.). Spain: Santa Cruz de Tenerife, 105-113.

15. Slepchenko S.M., Gusev A.V., Fedorova N.V., Ivanov S.N., Svyatova E.O. Archaeoparasitological and palynological analysis of samples from intestinal contents of a child mummy from Zelyeny Yar burial ground (XII-XIII centuries AD). Iran J Parasitol, in press.

16. Song M.K., Shin D.H. (2014). Joseon mummies before mummy studies began in Korea. Papers on Anthropology, 23, 1, 135-151.

https://doi.org/10.12697/poa.2014.23.1.12

17. Suzhou Museum and Culture Center of Jiangyin. (1982). The tomb of Sun Siniangzi of the Norther Song Dynasty at Jiangyin. Wenwu, 12, 28-35.

18. Taizhou Municipal Museum. (1986). Excavation of the Ming Dynasty Tomb of $\mathrm{Xu}$ Fan and His Wife at Taizhou, Jiangsu. Wenwu, 9, 1-15.

19. Taizhou Municipal Museum. (1992). Excavation of the Ming Joint Burial Tomb of Liu Xiang and His Wife at Taizhou City, Jiangsu. Wenwu, 9, 66-77.

20. Taizhou Municipal Museum. (2003). Excavation of a tomb of the Ming Dynasty of Zhu Shugui's wife Wu at Nanchang. Wenwu, 2, 20.

21. Taizhou Municipal Museum. (2013). The excavation of a tomb of the Ming Dynasty at Sensenzhuang in Taizhou City, Jiangsu. Wenwu, 11, 36-49. 
22. Wang W.G. and Zhang W. (2012). Analysis of Antisepsis techniques of the Ming-period corpse excavated in Taizhou. Zhonghua Yi Shi Za Zhi, 42, 1, $12-14$.

23. Zhou D., Zhou Y., Yang M. (1999). De`an Nan Song Zhou Shi Mu. Nanchang: Jiangxi ren min chu ban she.

\section{Address for correspondence:}

Professor Dr Dong Hoon Shin

Laboratory of Bioanthropology, Paleopathology and History of Diseases

Department of Anatomy / Institute of Forensic Science

Seoul National University College of Medicine

Seoul 03080, South Korea 